\title{
Preventative effect of diclofenac sodium and/or diltiazem in rats with epidural fibrosis
}

\author{
Erdogan $\mathrm{B}^{1}$, Is $\mathrm{M}^{2}$, Aker $\mathrm{FV}^{3}$, Emon $\mathrm{ST}^{4}$, Engin $\mathrm{T}^{5}$, Akar $\mathrm{EA}^{4}$, Sayman $\mathrm{E}^{3}$, Somay $\mathrm{H}^{4}$ \\ Sanliurfa Training and Research Hospital, Department of Neurosurgery, Sanliurfa, Turkey. \\ dr.baris.erdogan@gmail.com
}

\begin{abstract}
OBJECTIVE: Spinal epidural fibrosis is commonly seen after laminectomy. There is not yet proven any agent preventing fibrosis in clinical usage. We used diclofenac sodium and diltiazem, which are fibrosis inhibitors. METHODS AND MATERIALS: 40 rats were divided into four groups of equal numbers: control, diclofenac sodium, diltiazem, and diclofenac sodium + diltiazem. Laminectomies were performed at L5 and L6. After a 4 week period, the rats were decapitated and the vertebral column blocks were removed for histopathologic examination. Fibrosis percentage, spread of fibrous regions, and fibroblast numbers were evaluated in each group and compared between the groups.

RESULTS: The distribution of epidural fibrosis density, percentage of fibrosis, and distribution of fibroblasts in the diclofenac sodium + diltiazem group were significantly lower than in the other groups. The fibroblast numbers of the diltiazem, and diclofenac sodium + diltiazem groups were significantly lower than in the other groups.

CONCLUSION: Diclofenac sodium + diltiazem used together provided better outcomes because each of them prevented fibrosis via different ways, probably through synergistic action (Tab. 5, Fig. 3, Ref. 43). Text in PDF www.elis.sk.

KEY WORDS: diltiazem, diclofenac sodium, epidural fibrosis, laminectomy.
\end{abstract}

\begin{abstract}
Abbreviations: CMC/PEO - Carboxy Methyl Cellulose/ Poly Ethylene Oxide, C - Control, COX-2 - Cyclooxygenase-2, DK-Na Diclofenac sodium, DTZ - Diltiazem, DTZ + DK-Na - Diltiazem + diclofenac sodium, EF - Epidural fibrosis, FBBS - Failed Back Surgery Syndrome, FGF-2 - Fibroblast growth factor-2, IL-6 - Interleukin 6, IL-8 - Interleukin 8, MS - Medulla spinalis, NSAID - Non-Steroidal Anti-inflammatory Drugs, PGE - Prostaglandin, PGE-1 - Prostaglandin E1, PGE-2 - Prostaglandin E2, TGF- $\beta 1$ Transforming Growth Factor Beta 1, TNF - Tumor necrosis factor
\end{abstract}

\section{Introduction}

Epidural fibrosis (EF) is the development of the deposition of dense scar tissue adjacent to the dura mater, which distorts normal tissue architecture following laminectomy (1). Intra-operative

${ }^{1}$ Sanliurfa Training and Research Hospital, Department of Neurosurgery,
Sanliurfa, Turkey, ${ }^{2}$ Health Sciences University, Fatih Sultan Mehmet Train-
ing and Research Hospital, Department of Neurosurgery, Istanbul, Turkey,
${ }^{3}$ Health Sciences University, Haydarpasa Numune Training and Research
Hospital, Department of Pathology, Istanbul, Turkey, ${ }^{4}$ Health Sciences
University, Haydarpasa Numune Training and Research Hospital, Depart-
ment of Neurosurgery, Istanbul, Turkey, and ${ }^{5}$ Health Sciences University,
Mehmet Akif İnan Training and Research Hospital, Department of Neu-
rosurgery, Sanliurfa, Turkey

Address for correspondence: B. Erdogan, MD, Sanliurfa Training and Research Hospital, Department of Neurosurgery, Yenice yolu- Eyyübiye, Sanliurfa, Turkey.

Phone: +904143171717 dura mater injury, nerve root damage, excessive intra-operative bleeding cause EF. Epidural fibrosis accounts for approximately $8-14 \%$ of failed back surgery syndrome (FBSS) (2). EF presents either as painless or with a severe pain in the back and legs. When epidural fibrosis tissue is compared to normal tissue, interleukin (IL)-6, IL-8, tumor necrosis factor (TNF)- $\alpha$, and Transforming Growth Factor Beta 1 (TGF- $\beta 1$ ) are observed to increase in the EF tissue. Prostaglandin E1 and E2, and leukotriene B were found to contribute to the accumulation of these substances $(3,4)$.

Many methods have been used to prevent EF. Non-steroidal anti-inflammatory drugs (NSAIDs) (5), calcium channel blockers (6), pegaptanid sodium (7), mitomycin-C (2), hemostatic polysaccharide agents have been administered (8). All-trans retinoic acid (9), human amniotic fluid-sodium hyaluranate (10), poly (D, L-lactic acid-co-glycolic acid)-b-poly (ethylene glycol)-b-poly (D, L-lactic acid-co-glycolic acid) thermogel (11), etarnacept (12), dekorin (13), CMC/PO (14), licofelone (15), temozolamide (16), polymethylmethacrylate (17) and hyperbaric oxygen (18) are examples of other agents that have been studied in the treatment of spinal EF.

Diclofenac sodium acts by inhibiting cyclooxygenase-2 (COX2) $(19,20)$. Some studies have shown it to modulate collagen synthesis by inhibiting prostaglandin E2 (PGE-2) and reducing fibroblast proliferation in colon cells. Diclofenac sodium reduces the numbers and mechanical strength of fibroblast in local wound healing (21-23). Diltiazem was shown to inhibit fibroblast growth factor-2 (FGF-2), reduce numbers of heart fibroblast cells, pro- 
Tab. 1. He et al's grading system.

\begin{tabular}{ll}
\hline Grade 0 & Dura free of scar tissue \\
\hline Grade 1 & Only thin fibrous bands between the scar tissue and dura \\
\hline Grade 2 & $\begin{array}{l}\text { Continuous adherence in less than two-thirds of the laminec- } \\
\text { tomy defect }\end{array}$ \\
\hline Grade 3 & $\begin{array}{l}\text { Significant scar tissue adherence affecting more than two-thirds } \\
\text { of the laminectomy }\end{array}$
\end{tabular}

According to their system; grade $0=$ dura is free of scar tissue, grade $1=$ only thin fibrous bands between the scar tissue and dura, grade 2 = continuous adherence in less than two-thirds of the laminectomy defect, and grade $3=$ significant scar tissue adherence affecting more than two-thirds of the laminectomy defect

liferate human tendon fibroblasts and reduce fibroblast linkage, increase the amount of superoxide dismutase in heart fibroblast cells and assist remodeling after a cardiac injury (24-28). In light of these studies, we considered that diclofenac sodium and/or diltiazem might reduce EF. It was planned to use diclofenac sodium and diltiazem together and separately in our study.

\section{Materials and methods}

Our experimental study was conducted after receiving the approval from the Marmara University Animal Experiments Local Ethics Committee (protocol code: 044.2016 date: 06/06/2016) at Marmara University Experimental Animal Laboratory (DEHAM). Histopathologic examinations were performed in the Haydarpaşa Numune Training and Research Hospital Pathology clinic.

The rats were divided into 4 groups: control (C), diltiazem (DTZ), diclofenac sodium (DK-Na) and diltiazem + diclofenac sodium (DTZ + DK-Na). The rats were anesthetized using an intraperitoneal injection of ketamine hydrochloride (Ketalar 100 $\mathrm{mg} / \mathrm{kg}$ (ip), Pfizer, Istanbul) and xylazine hydrochloride (Rompun $10 \mathrm{mg} / \mathrm{kg}$ (ip), Rompun $2 \%$, Bayer, Istanbul, Turkey). The rats were placed on an operating board in the prone position. After the L5 and L6 skin level was detected, the skin was shaved. The surgical field was disinfected using povidone-iodine (POVIOD $10 \%$ polyvinyl pyrrolidone-iodine complex, Saba, Turkey) and

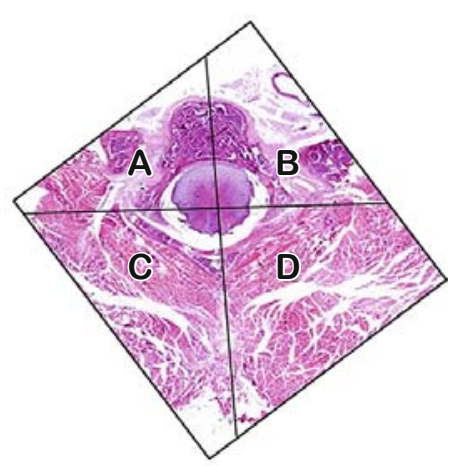

Fig. 1. We modified Lubina et al.'s grading system. We used a light microscope instead of MRI. We divided an axial vertebra into four regions. One line between the middle of the corpus vertebra to the spinous process of the vertebra, and another line between the two transverse processes of the vertebra. We named the regions as $A, B, C$, and D. We calculated the percentage of fibrosis for each region and as atol.

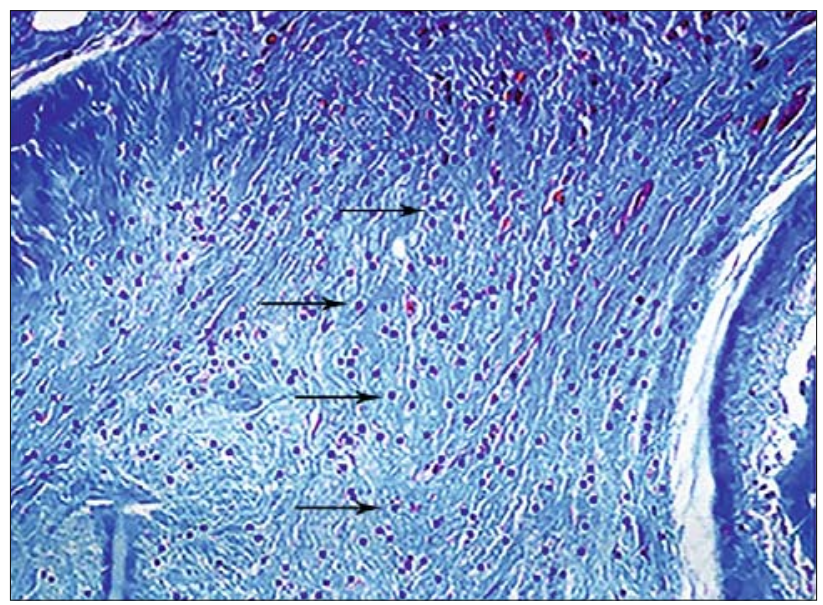

Fig. 2. We calculated the number of fibroblasts in digital system, which stained with Masson's trichrome examples. The arrows show fibroblasts.

draped with sterile towels. A midline dorsal skin incision was made using a number- 15 blade and continued down to the spinous process. The paravertebral muscles were bluntly dissected. L5 and L6 lamina were exposed. Laminectomy was performed on the L5 and L6 vertebrae. The dura mater was exposed. In the control group, the dura mater was only irrigated with saline. In the diltiazem group, cotton pads $\left(4 \times 4 \mathrm{~mm}^{2}\right)$ soaked with DTZ $5 \mathrm{mg} / \mathrm{mL}$ were applied to the exposed dura mater for 5 minutes. The cotton wool was then removed and the laminectomy site was irrigated with saline. In the DK-Na group, cotton pads $(4 \mathrm{x} 4$ $\mathrm{mm}^{2}$ ) soaked with DK-Na $25 \mathrm{mg} / \mathrm{mL}$ were applied to the exposed dura mater for 5 minutes. The cotton wool was removed and the laminectomy site was irrigated with saline. In the DTZ + DK-Na group, cotton pads $\left(4 \times 4 \mathrm{~mm}^{2}\right)$ soaked with $5 \mathrm{mg} / \mathrm{mL} \mathrm{DTZ}$ and $25 \mathrm{mg} / \mathrm{mL}$ DK-Na were applied to the exposed dura for $5 \mathrm{~min}$ utes. The cotton wool was then removed and the laminectomy site was irrigated with saline. Following hemostasis, the wound was closed in accordance with the anatomy using staples. There were no complications or adverse effects from the surgery. The rats were taken to their cages.

The rats were closely monitored for dehydration, infection, body weight, feeding, and wounds in the post-operative period. Post-dressings were made daily until the 7th day and staples were removed on the 7th day. Intra-peritoneal saline was administered to dehydrated animals. Seven rats were lost in the postoperative period. The study continued with the remaining 33 rats. The rats were decapitated on post-op day 28 using a guillotine. The rats were examined at the Haydarpaşa Numune Training and Research Hospital Pathology Clinic for histopathologic changes.

\section{Histopathological examination and classification}

The vertebral colon was removed as a block containing the L5 and L6 levels. The entire sampling/lesion area was sampled in coronal planar sections. Samples were fixed in $10 \%$ buffered formaldehyde for 48 hours. Afterwards, the samples were taken to a "short decalcification solution" and the bone tissue was allowed to soften. Samples with an appropriate softness were taken 

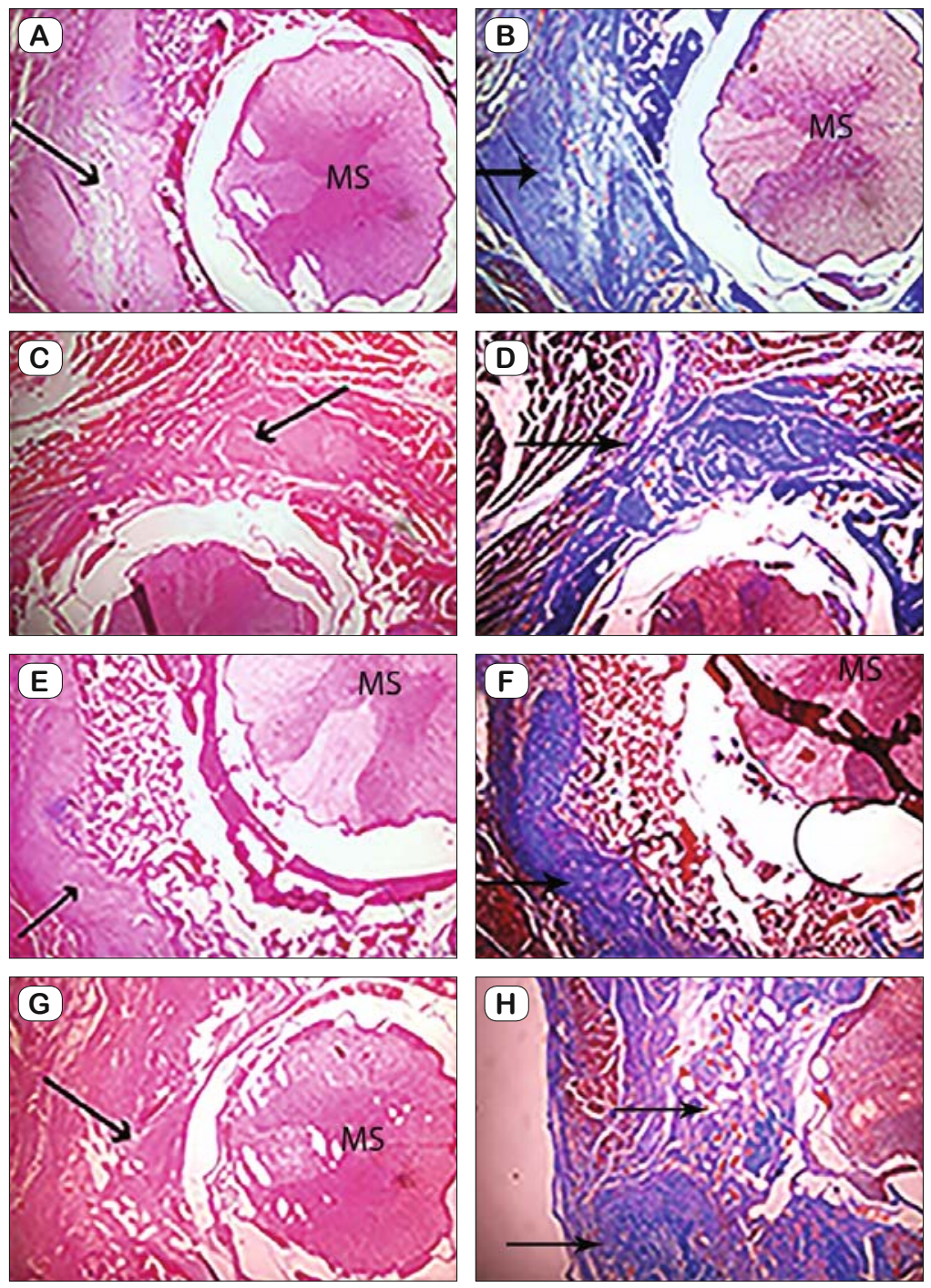

Fig. 3. A) The pictures show an example of DTZ. The picture is stained with hematoxylin and eosin. The arrows show fibrosis, which occur after trauma.

B) The pictures show an example of DTZ. The picture is stained with Masson's trichrome. The arrows show fibrosis, which occur after trauma.

C) The pictures show an example of control. The picture is stained with hematoxylin and eosin. The arrows show fibrosis, which occur after trauma.

D) The pictures show an example of control. The picture is stained with Masson's trichrome. The arrows show fibrosis, which occur after trauma.

E) The pictures show examples of DTZ + DK-Na. The picture is stained with hematoxylin and eosin. The arrows show fibrosis, which occur after trauma.

F) The pictures show examples of DTZ + DK-Na. The picture is stained with Masson's trichrome. The arrows show fibrosis, which occur after trauma.

G) The pictures show examples of DK-Na. The picture is stained with hematoxylin and eosin. The arrows show fibrosis, which occur after trauma.

H) The pictures show examples of DK-Na. The picture is stained with Masson's trichrome. The arrows show fibrosis, which occur after trauma. MS - Medulla spinalis. Hematoxylin-eosin and Masson's trichrome X40.

following a routine tissue examination. After 18 hours of routine tissue processing, the tissue was embedded in paraffin blocks and cut to a thickness of 4-5 microns. It was stained using hematoxylin and eosin. In addition, a special histochemistry stain, Masson's trichrome, was used in selective blocks that represented the best of the lesion area in order to assess fibrosis. Sections were evaluated by a light microscopy.

We modified Lubina et al's grading system. We used a light microscope instead of magnetic resonance imaging (MRI) for epidural fibrosis assessment. We evaluated EF using He et al.'s grading system and our modified Lubina grading system $(29,30)$ (Tab. 1, Fig. 1). In addition, we calculated the number of fibroblasts in each group and compared the findings between the groups (Fig. 2).

\section{Statistical investigations}

Statistical analysis was performed using the NCSS (Number Cruncher Statistical System) 2007 Statistical Software (Utah, USA) program. The Kruskal-Wallis test was used for comparison of non-normally distributed data using descriptive statistical methods (mean, standard deviation, median, frequency, ratio), and the Mann-Whitney U test was used to determine the differences between the groups. The Fisher-Freeman-Halton test was used to compare qualitative data. The results were evaluated with a confidence interval of $95 \%$ and a significance level of $\mathrm{p}<0.05$.

\section{Results}

The He grade of all animals in the DTZ + DK$\mathrm{Na}$ (Fig. 3 E, F) group were grade 1 and significantly lower than those of the control (Fig. $3 \mathrm{C}$, D), DK-Na (Fig. 3 G, H), and DTZ groups (Fig. 3 A, B, Tab. 2). The modified Lubina grading system percentages in the DK-Na + DTZ group were significantly lower than those of the control, DK-Na, and DTZ groups $(\mathrm{p}=0.004, \mathrm{p}=0.013$, and $\mathrm{p}=$ 0.038 , respectively) (Tabs 3 and 4). The numbers of fibroblasts in the $\mathrm{g}$ DTZ + DK-Na group were significantly lower than in the control and DKNa groups $(p=0.033, p=0.003$, respectively). The number of fibroblasts in the DTZ group was significantly lower than in the DK-Na group $(\mathrm{p}=$ $0.028, \mathrm{p}<0.05)($ Tab. 5).

\section{Discussion}

Epidural scar tissue develops following a spinal surgery, when epidural fat is replaced by a hematoma. This hematoma is absorbed and replaced by granulation tissue $(31,32)$. Dense EF causes nerve root irritation, entrapment, restriction of nerve root mobility, and a direct dural compression, which is the main reason for pain in the back and leg (33). Postoperative epidural fibrosis following a lumbar disc surgery significantly increases the hazards of the revision of spine surgery and contributes to the occurrence of FBSS. FBSS can be seen in 10-40\% 
of lumbar spine operations. Postoperative pain is correlated to EF amounts $(34,35)$.

Several methods were used to prevent EF. These methods include microdiscectomy, anti-inflammatory drug use, various biologic and synthetic materials (oil graft, amniotic membrane,

Tab. 2. Asessment of groups according to the He grading system.

\begin{tabular}{llcccc}
\hline & & \multicolumn{4}{c}{ Groups } \\
\cline { 3 - 6 } & & Control & DK-Na & DTZ & DTZ + DK-Na \\
\hline He & Grade 1 & $3(37.5)$ & $4(57.1)$ & $3(37.5)$ & $10(100)$ \\
& Grade 2 & $4(50.0)$ & $2(28.6)$ & $4(50.0)$ & 0 \\
& Grade 3 & $1(12.5)$ & $1(14.3)$ & $1(12.5)$ & 0 \\
\hline p & \multicolumn{5}{c}{$0.031^{*}$} \\
\hline
\end{tabular}

Fisher-Freeman-Halton test $* \mathrm{p}<0.05$

There were statistically significant differences between the groups according to $\mathrm{He}$ grading system $(\mathrm{p}<0.05)$. We compared the groups with each other to determine, which group or groups caused the differences. The DTZ + DK-Na group had only grade 1 and it was found significantly less than in the other groups.

Tab. 3. Distribution according to modified Lubina Grading system.

\begin{tabular}{|c|c|c|c|c|c|c|c|c|c|}
\hline & & \multicolumn{7}{|c|}{ Modified Lubina Grading system } & \multirow{2}{*}{${ }^{\mathrm{a} p}$} \\
\hline & & Negative & 1 & 2 & 3 & 4 & Mean+SD & Median & \\
\hline \multirow{4}{*}{ C Region } & Control & 0 & 1 & 3 & 4 & 0 & $2.38+0.74$ & 2.5 & \multirow{4}{*}{$0.005^{* *}$} \\
\hline & $\mathrm{DK}-\mathrm{Na}$ & 0 & 1 & 4 & 1 & 1 & $2.29+0.95$ & 2 & \\
\hline & DTZ & 0 & 3 & 4 & 1 & 0 & $1.75+0.71$ & 2 & \\
\hline & $\mathrm{DTZ}+\mathrm{DK}-\mathrm{Na}$ & 2 & 6 & 2 & 0 & 0 & $1+0.67$ & 1 & \\
\hline
\end{tabular}

${ }^{\mathrm{a}}$ Kruskal-Wallis test $* * \mathrm{p}<0.01$

Our modified Lubina grading system showed region $\mathrm{C}$ had a statistically significant difference $(\mathrm{p}<0.05)$. We compared the groups with each other to determine, which group or groups caused the differences. DTZ + DK-Na group's median value was statistically significantly lower than the control, DK-Na, and DTZ groups $(0.003 ; \mathrm{p}=0.007 ; \mathrm{p}$ $=0.042$, respectively)

Tab. 4. Assessment of percentage values according to groups in the modified Lubina Grading system.

\begin{tabular}{|c|c|c|c|c|c|}
\hline & & \multicolumn{4}{|c|}{ Groups } \\
\hline & & Control & DK.Na & DTZ & DTZ+DK.Na \\
\hline \multirow{3}{*}{$\begin{array}{l}\text { Modified Lubina } \\
\text { Percent (\%) }\end{array}$} & Mean+SD & $32.03+12.25$ & $29.54+12.36$ & $27.41+16.02$ & $15.63+6.75$ \\
\hline & Min-Max & $12.5-50$ & $12.5>50$ & $12.5-62.5$ & $6.25-25$ \\
\hline & Median & 31.25 & 31.5 & 25 & 12.5 \\
\hline${ }^{\mathrm{a}} \mathrm{p}$ & & \multicolumn{4}{|c|}{$0.016^{*}$} \\
\hline${ }^{\mathrm{b} C o n t r o l-D T Z}+\mathrm{L}$ & & \multicolumn{4}{|c|}{$0.004 * *$} \\
\hline${ }^{\mathrm{b} D T Z}-\mathrm{DTZ}+\mathrm{DK}$ & & \multicolumn{4}{|c|}{$0.038^{*}$} \\
\hline
\end{tabular}

${ }^{\mathrm{a}}$ Kruskal-Wallis test, ${ }^{\mathrm{b}} \mathrm{Mann}-$ Whitney U test $* \mathrm{p}<0.05 * * \mathrm{p}<0.01$

The modified Lubina system's percentage measurement showed a statistically significant difference $(\mathrm{p}<0.05)$. We compared the groups with each other to determine, which group or groups caused the differences. The DTZ + DK-Na group has a statistically significantly lower modified Lubina system's percentage than the control, DK-Na, and DTZ groups ( $\mathrm{p}=0.004 ; \mathrm{p}=0.013 ; \mathrm{p}=0.038$, respectively)

Tab. 5. Assessment of fibroblast number according to groups.

\begin{tabular}{|c|c|c|c|c|c|}
\hline & & \multicolumn{4}{|c|}{ Groups } \\
\hline & & Control & $\mathrm{DK}-\mathrm{Na}$ & DTZ & $\mathrm{DTZ}+\mathrm{DK}-\mathrm{Na}$ \\
\hline \multirow{3}{*}{$\begin{array}{l}\text { Fibroblast } \\
\text { number }\end{array}$} & Mean+SD & $474.13+180.43$ & $483.14+110.22$ & $330.5+104.71$ & $310.4+64,9$ \\
\hline & Min-Max & 195-705 & 296-648 & $234-538$ & 234-393 \\
\hline & Median & 489.5 & 506 & 284.5 & 305.5 \\
\hline \multicolumn{2}{|l|}{${ }^{a} p$} & \multicolumn{4}{|c|}{$0.014^{*}$} \\
\hline \multicolumn{2}{|c|}{${ }^{\mathrm{b}}$ Control - DTZ+DK-Na } & \multicolumn{4}{|c|}{$0.033^{*}$} \\
\hline \multicolumn{2}{|c|}{${ }^{\mathrm{b}} \mathrm{DK}-\mathrm{Na}-\mathrm{DTZ}+\mathrm{DK}-\mathrm{Na}$} & \multicolumn{4}{|c|}{$0.003 * *$} \\
\hline
\end{tabular}

${ }^{\mathrm{a}}$ Kruskal-Wallis test, ${ }^{\mathrm{b}}$ Mann-Whitney U test, ${ }^{*} \mathrm{p}<0.05, * * \mathrm{p}<0.01$

Fibroblast numbers showed a statistically significant difference $(\mathrm{p}<0.05)$. We compared the groups with each other to determine, which group or groups caused the differences. DTZ + DK-Na group's fibroblast number was statistically significantly lower than in the control and DK-Na groups' $(\mathrm{p}=0.033$; $\mathrm{p}=0.003$ ). The DTZ group's fibroblast numbers was statistically significantly lower than the DK-Na group $(\mathrm{p}=0.028 ; \mathrm{p}<0.05)$ 
reaction of inflammation in the damage of certain tissue. Histochemical analysis of tissue has shown a reduction of TNF- $\alpha$ and IL-8, both of which have pro-inflammatory effects (4). Thus, DTZ reduces inflammation. DTZ and DK-Na reduced inflammation in different ways, showing synergistic action; used together, both provided better outcomes.

In our study, the combined DTZ + DK-Na group had a significantly lower EF density, had a significantly lower fibrosis percentage, and had significantly less fibrosis in the $\mathrm{C}$ region of the vertebra than in other groups (Fig. 1). We determined that the DTZ + DK-Na group and the DTZ group had significantly lower fibroblast numbers than the DK-Na group and the control group.

We believe that DTZ and DK-Na were more effective when they were used together because they inhibited inflammation in different ways.

\section{Conclusion}

Laminectomy is the most commonly used method in neurosurgery practice. Post-operative persistent back and leg pain is recognized as FBSS. FBSS, caused by EF, adversely affects the quality of patients' lives socially, as well as economically and psychologically.

We assessed DK-Na and DTZ in the prevention of EF. Both are cheap and readily available. We determined that by the administration of these drugs prior to closing the surgical area, the formation of EF was significantly reduced. However, neither DK-Na nor DTZ have been used in the treatment of EF. Our findings are based on experiments performed on a limited number of animals only; any effect on humans at this stage is unknown. More studies of this area are required before there may be any potential clinical use of these entities with the objective of reducing EF.

\section{References}

1. Emmez H, Kardes O, Dogulu F, Kurt G, Memis L, Baykaner MK. Role of antifibrotic cytokine interferon- $\gamma$ in the prevention of postlaminectomy peridural fibrosis in rats. Neurosurgery 2008; 62: 1351-1358. doi: 10.1227/01.neu.0000333307.02802.04.

2. Yildiz KH, Gezen F, Is M, Cukur S, Dosoglu M. Mitomycin C, 5-fluorouracil, and cyclosporin A prevent epidural fibrosis in an experimental laminectomy model. Eur Spine J 2007; 16: 1525-1530. doi: 10.1007/ s00586-007-0344-8.

3. Selcuk A, Akdogan O, Ozcan I, Giray SG, Dere H, Ozogul C. Topical Application of Calcium Channel Blockers to Reduce the Progression of Experimentally Induced Myringosclerosis and Tympanosclerosis. Laryngoscope 2008; 118: 697-705. doi: 10.1097/MLG.0b013e31815 ed115.

4. Bai Y, Hu L, Wu J, Gu Y, Li L, Gao B et al. Effects of intravenous diltiazem in a rat model of experimental coronary thrombotic microembolism. Exp Ther Med 2013; 6: 873-882. doi: 10.3892/etm.2013.1263.

5. Sandoval MA, Hernandez-Vaquero D. Preventing peridural fibrosis with nonsteroidal anti-inflammatory drugs. Eur Spine J 2008; 17: 451-455. doi: $10.1007 / \mathrm{s} 00586-007-0580-y$.
6. Wang Z, Wang Y, Xie P, Liu W, Zhang S. Calcium channel blockers in reduction of epidural fibrosis and dural adhesions in laminectomy rats. Eur J Orthop Surg Traumatol 2014; 24: 293-298. doi: 10.1007/s00590013-1395-7.

7. Sertbas I, Yilmaz A, Yildirim T, Karatay M, Celik H, Bayar MA. The role of pegaptanib sodium in the suppression of epidural fibrosis in a postlaminectomy rat model. Bratisl Lek Listy 2017; 118: 118-122. doi: 10.4149/BLL_2017_024.

8. Tural Emon S, Somay H, Orakdogen M, Uslu S, Somay A. Effects of hemostatic polysaccharide agent on epidural fibrosis formation after lumbar laminectomy in rats. Spine J 2016; 16: 414-419. doi: 10.1016/j. spinee.2015.11.014.

9. Zhang C, Kong X, Ning G, Liang Z, Qu T, Chen F et al. All-trans retinoic acid prevents epidural fibrosis through $\mathrm{NF}-\mathrm{kB}$ signaling pathway in post-laminectomy rats. Neuropharmacology 2014; 79: 275-281. doi: 10.1016/j.neuropharm.2013.11.010.

10. Bolat E, Kocamaz E, Kulahcilar Z, Yilmaz A, Topcu A, Ozdemir M et al. Investigation of Efficacy of Mitomycin-C, Sodium Hyaluronate and Human Amniotic Fluid in Preventing Epidural Fibrosis and Adhesion Using a Rat Laminectomy Model. Asian Spine J 2013; 7: 253. doi: 10.4184/asj.2013.7.4.253

11. Li X, Chen L, Lin H, Cao L, Cheng J, Dong $J$ et al. Efficacy of Poly(D,L-Lactic Acid-co-Glycolic acid)-Poly(Ethylene Glycol)-Poly(D,LLactic Acid-co-Glycolic Acid) Thermogel As a Barrier to Prevent Spinal Epidural Fibrosis in a Postlaminectomy Rat Model. Clin Spine Surg 2017; 30: E283-290. doi: 10.1097/BSD.0000000000000221.

12. Turkoglu E, Tuncer C, Dinc C, Serbes G, Oktay M, Sekercı Z. The Effect of Etanercept on Spinal Epidural Fibrosis in a Postlaminectomy Rat Model. Turk Neurosurg 2014; 24: 6.

13. Turkoglu E, Dinc C, Tuncer C, Oktay M, Serbes G, Sekerci Z. Use of decorin to prevent epidural fibrosis in a post-laminectomy rat model. Eur J Pharmacol 2014; 724: 86-91. doi: 10.1016/j.ejphar.2013.12.017.

14. Liu Z, Li Y, Zang Y, Cui G, Sang H, Ma Z et al. Clinical assessment of a $\mathrm{CMC} / \mathrm{PEO}$ gel to inhibit postoperative epidural adhesion formation after lumbar discectomy: a randomized, control study. Arch Orthop Trauma Surg 2013; 133: 295-301. doi: 10.1007/s00402-012-1634-0.

15. Zhang K, Zhao J, Su W, Lu R, Lv P. Immunomodulatory effectiveness of licofelone in preventing epidural fibrosis in post-laminectomy rat. Eur J Orthop Surg Traumatol 2015; 25: 63-68. doi: 10.1007/s00590014-1534-9.

16. Aydincak O, Yilmaz MB, Emmez H, Kurt G, Sepici A, Memis L et al. The effect of temozolomide on the prevention of epidural fibrosis developing after lumbar laminectomy in rats. Turk Neurosurg 2012. doi: 10.5137/1019-5149.JTN.5966-12.1.

17. Silva González A, Alfonso Olmos M, Villas Tomé C, Angulo MG. Model of Induced Leakage of Polymethylmethacrilate Inside Epidural Space and Prevertebral Muscles During Vertebroplasty in Pigs: Clinical, Macroscopical, and Histological Study. Asian Spine J 2013; 7: 159. doi: 10.4184/asj.2013.7.3.159.

18. Lv P, Zhao J, Su W, Liang X, Zhang K. An experimental novel study: hyperbaric oxygen treatment on reduction of epidural fibrosis via downregulation of collagen deposition, IL-6, and TGF- $\beta 1$. Eur J Orthop Surg Traumatol 2015; 25: 53-58. doi: 10.1007/s00590-014-1509-x.

19. Yurt KK, Kaplan S. As a painkiller: a review of pre- and postnatal nonsteroidal anti-inflammatory drug exposure effects on the nervous systems. Inflammopharmacology 2018;26: 15-28. doi: 10.1007/s10787-017-0434-0. 
813-818

20. Li Y, Lei D, Swindell WR, Xia W, Weng S, Fu J et al. Age-Associated Increase in Skin Fibroblast-Derived Prostaglandin E 2 Contributes to Reduced Collagen Levels in Elderly Human Skin. J Invest Dermatol 2015; 135: 2181-2188. doi: 10.1038/jid.2015.157.

21. Al-Nimer MSM, Hameed HG, Mahmood MM. Antiproliferative effects of aspirin and diclofenac against the growth of cancer and fibroblast cells: In vitro comparative study. Saudi Pharmaceutical J 2015; 23 : 483-486. doi: 10.1016/j.jsps.2015.01.002

22. Krischak GD, Augat P, Claes L, Kinzl L, Beck A. The effects of nonsteroidal anti-inflammatory drug application on incisional wound healing in rats. J Wound Care 2007; 16: 76-78. doi: 10.12968/jowc.2007.16.2.27001.

23. Shivakumar K, Kumaran C. L-type Calcium Channel Blockers and EGTA Enhance Superoxide Production in Cardiac Fibroblasts. J Mol Cell Cardiol 2001; 33: 373-377. doi: 10.1006/jmcc.2000.1309.

24. Graudins A, Lee HM, Druda D. Calcium channel antagonist and beta-blocker overdose: antidotes and adjunct therapies: Management of CCB and beta-blocker toxicity. Brit J Clin Pharmacol 2016; 81: 453-461. doi: 10.1111/bcp.12763.

25. Takano Y, Ohguro H, Dezawa M, Ishikawa H, Yamazaki H, Ohguro I et al. Study of drug effects of calcium channel blockers on retinal degeneration of rd mouse. Biochem Biophys Res Comm 2004; 313 : 1015-1022. doi: 10.1016/j.bbrc.2003.12.034.

26. Walsh KB, Zhang J, Fuseler JW, Hilliard N, Hockerman GH. Adenoviral-mediated expression of dihydropyridine-insensitive L-type calcium channels in cardiac ventricular myocytes and fibroblasts. Eur J Pharmacol 2007; 565: 7-16. doi: 10.1016/j.ejphar.2007.02.049.

27. Yue H, Uzui H, Shimizu H, Nakano A, Mitsuke Y, Ueda T et al. Different Effects of Calcium Channel Blockers on Matrix Metalloproteinase-2 Expression in Cultured Rat Cardiac Fibroblasts: J Cardiovasc Pharmacol 2004; 44: 223-230. doi: 10.1097/00005344-200408000-00012.

28. He Y, Revel M, Loty B. A quantitative model of post-laminectomy scar formation. Effects of a nonsteroidal anti-inflammatory drug. Spine 1995; 20: 557-563; discussion 579-580.

29. Lubina ZI, Baranovic S, Karlak I, Novacic K, Potocki-Karacic T, Lovrić $\mathbf{D}$. The grading model for the assessment of the total amount of epidural fibrosis in postoperative lumbar spine. Eur Spine J 2013; 22 : 892-897. doi: 10.1007/s00586-012-2537-z.

30. LaRocca H, Macnab I. The laminectomy membrane. Studies in its evolution, characteristics, effects and prophylaxis in dogs. J Bone Joint Surg Br 1974; 56B: 545-550.

31. Songer MN, Rauschning W, Carson EW, Pandit SM. Analysis of peridural scar formation and its prevention after lumbar laminotomy and discectomy in dogs. Spine 1995; 20: 571-580; discussion 579-580.
32. Nussbaum CE, McDonald JV, Baggs RB. Use of Vicryl (polyglactin 910) mesh to limit epidural scar formation after laminectomy. Neurosurgery 1990; 26: 649-654.

33. Desai MJ, Nava A, Rigoard P, Shah B, Taylor RS. Optimal medi$\mathrm{cal}$, rehabilitation and behavioral management in the setting of failed back surgery syndrome. Neurochirurgie 2015; 61: S66-76. doi: 10.1016/j.neuchi.2014.09.002.

34. Sebaaly A, Lahoud M-J, Rizkallah M, Kreichati G, Kharrat K. Etiology, Evaluation, and Treatment of Failed Back Surgery Syndrome. Asian Spine J 2018; 12: 574-85. doi: 10.4184/asj.2018.12.3.574.

35. Alkalay RN, Kim DH, Urry DW, Xu J, Parker TM, Glazer PA. Prevention of Postlaminectomy Epidural Fibrosis Using Bioelastic Materials. Spine 2003; 28: 1659-1665. doi: 10.1097/01.BRS.0000083161.67605.40.

36. Sun Y, Ge Y, Fu Y, Yan L, Cai J, Shi K et al. Mitomycin C induces fibroblasts apoptosis and reduces epidural fibrosis by regulating miR$200 \mathrm{~b}$ and its targeting of RhoE. Eur J Pharmacol 2015; 765: 198-208. doi: 10.1016/j.ejphar.2015.08.002.

37. Xie H, Wang B, Shen X, Qin J, Jiang L, Yu C et al. MMC controlled-release membranes attenuate epidural scar formation in rat models after laminectomy. Mol Med Rep 2017; 15: 4162-4168. doi: 10.3892/ mmr.2017.6531.

38. Quist JJ, Dhert WJA, Meij BP, Visser WJ, Oner FC, Hazewinkel HAW et al. The prevention of peridural adhesions. J Bone Joint Surg 1998; 80: 7.

39. Wang H, Sun W, Fu D, Shen Y, Chen Y, Wang L. Update on biomaterials for prevention of epidural adhesion after lumbar laminectomy. J Orthop Translation 2018; 13: 41-49. doi: 10.1016/j.jot.2018.02.001.

40. Breyer RM, Bagdassarian CK, Myers SA, Breyer MD. Prostanoid Receptors : Subtypes and Signaling. Ann Rev Pharmacol Toxicol 2001; 41: 661-690. doi: 10.1146/annurev.pharmtox.41.1.661

41. Nakanishi M, Rosenberg DW. Multifaceted roles of PGE2 in inflammation and cancer. Semin Immunopathol 2013; 35: 123-137. doi: 10.1007/ s00281-012-0342-8.

42. Samuelsson B, Morgenstern R, Jakobsson PJ. Membrane Prostaglandin E Synthase-1: A Novel Therapeutic Target. Pharmacol Rev 2007; 59: 207-224. doi: 10.1124/pr.59.3.1.

43. Wang D, Mann JR, Dubois RN. The Role of Prostaglandins and Other Eicosanoids in the Gastrointestinal Tract. Gastroenterology 2005; 128: 1445-1461. doi: 10.1053/j.gastro.2004.09.080.

Received May 17, 2019. Accepted July 8, 2019. 